\title{
Association between anxiety and severe quality-of-life impairment in postmenopausal women: analysis of a multicenter Latin American cross-sectional study
}

Jorge L. Núnez-Pizarro, MD, ${ }^{1}$ Alejandro González-Luna, MD, ${ }^{1}$ Edward Mezones-Holguín, MD, MSc, ${ }^{1,2,3}$ Juan E. Blümel, MD, PhD, ${ }^{3,4}$ Germán Barón, MD, ${ }^{3}$ Ascanio Bencosme, MD, ${ }^{3}$ Zully Benitez, MD, ${ }^{3}$ Luz M. Bravo, MD, ${ }^{3}$ Andrés Calle, MD, ${ }^{3}$ Daniel Flores, MD, ${ }^{3}$ María T. Espinoza, MD, ${ }^{3}$ Gustavo Gómez, MD, ${ }^{3}$ José A. Hernández-Bueno, MD, ${ }^{3}$ Mabel Martino, MD, ${ }^{3}$ Selva Lima, MD, ${ }^{3}$ Alvaro Monterrosa, MD,,$^{3}$ Desiree Mostajo, MD, ${ }^{3}$ Eliana Ojeda, MD, ${ }^{3}$ William Onatra, MD, ${ }^{3}$ Hugo Sánchez, MD, ${ }^{3}$ Konstantinos Tserotas, MD, María S. Vallejo, MD ${ }^{3}$ Silvina Witis, MD, ${ }^{3}$ María C. Zúnïga, $M D{ }^{3}$ and Peter Chedraui, $M D, P h D^{3,5}$

\begin{abstract} American postmenopausal women. potentially confounding variables from literature review. 95\% CI, 1.2-1.6).

enopause marks the end of the female reproductive period. During the menopausal transition there is a progressive and irreversible decline of
\end{abstract}

Objective: To evaluate associations between anxiety and severe impairment of quality of life (QoL) in Latin

Methods: This was a secondary analysis of a multicenter cross-sectional study among postmenopausal women aged 40 to 59 from 11 Latin American countries. We evaluated anxiety (The Goldberg Depression and Anxiety Scale), and QoL (Menopause Rating Scale [MRS]), and included sociodemographic, clinical, lifestyle, and anthropometric variables in the analysis. Poisson family generalized linear models with robust standard errors were used to estimate prevalence ratios (PRs) and 95\% CIs. There were two adjusted models: a statistical model that included variables associated with the outcomes in bivariate analyses, and an epidemiologic model that included

Results: Data from 3,503 women were included; 61.9\% had anxiety (Goldberg). Severe QoL impairment (total MRS score $\geq 17$ ) was present in $13.7 \%$ of women, as well as severe symptoms (MRS subscales): urogenital (25.5\%), psychological (18.5\%), and somatic (4.5\%). Anxiety was independently associated with severe QoL impairment and severe symptoms in the epidemiological (MRS total score: PR 3.6, 95\% CI, 2.6-5.0; somatic: 5.1, 95\% CI, 2.6-10.1; psychological: 2.8, 95\% CI, 2.2-3.6; and urogenital: 1.4, 95\% CI, 1.2-1.6) and the statistical model (MRS total score: PR 3.5, 95\% CI, 2.6-4.9; somatic: 5.0, 95\% CI, 2.5-9.9; psychological: 2.9, 95\% CI, 2.2-3.7; and urogenital: 1.4;

Conclusions: In this postmenopausal Latin American sample, anxiety was independently associated with severe QoL impairment. Hence, screening for anxiety in this population is important.

Key Words: Anxiety - Climacteric - Latin America - Menopause - Quality of life - Symptoms.
Received May 17, 2016; revised and accepted October 26, 2016. From the ${ }^{1}$ Escuela de Medicina, Universidad Peruana de Ciencias Aplicadas (UPC), Lima, Perú: ${ }^{2}$ Intendencia de Investigación y Desarrollo, Superintendencia Nacional de Salud (SUSALUD), Lima, Perú; ${ }^{3}$ Collaborative Group for Research of the Climacteric in Latin America (REDLINC); ${ }^{4}$ Departamento de Medicina, Facultad de Medicina, Universidad de Chile, Santiago de Chile, Chile; and ${ }^{5}$ Instituto de Biomedicina, Facultad de Ciencias Médicas, Universidad Católica de Santiago de Guayaquil, Guayaquil, Ecuador.

Financial disclosure/conflicts of interest: K.T. states a financial relationship with Abbott and Merck Sharp \& Dohme.

Address correspondence to: Edward Mezones-Holguín, MD, MSc, Prolongación Primavera 2390, Monterrico, Santiago de Surco, Lima, Perú, Correo electrónico. E-mail: emezones@gmail.com ovarian function, which causes an array of symptoms. ${ }^{1,2}$ These can be severe enough to negatively impact female health and quality of life $(\mathrm{QoL}) .^{3-5}$ QoL encompasses several factors that require assessment and objective measuring for both epidemiological and clinical purposes, particularly during and after menopause. ${ }^{6}$ Indeed, hormonal changes may impact several domains such as the somatic-vegetative, psychological, and urogenital. ${ }^{7}$

Aside from hormonal changes, age, ${ }^{3,5,8}$ socioeconomic status, ${ }^{3,9}$ altitude of residency, ${ }^{3}$ ethnicity, and cultural aspects ${ }^{10,11}$ may also correlate with more intense menopausal symptoms and hence impaired QoL. On the other hand, lifestyle factors such as cigarette smoking, ${ }^{12}$ alcohol consumption, ${ }^{13}$ sedentary lifestyle, obesity, ${ }^{13,14}$ and mental illnesses, especially mood disorders such as anxiety and depression ${ }^{3}$ are also important. 


\section{NÚNEZ-PIZARRO ET AL}

Of the above-mentioned features, mood problems are of particular importance as they increase during the menopausal transition. ${ }^{15}$ In particular, the association between anxiety and QoL during female midlife is a topic of growing interest. ${ }^{16}$ Anxiety is highly prevalent during the peri- and early postmenopausal stage, ${ }^{15}$ mainly due to hormonal changes. ${ }^{17,18}$ In addition, other aspects seem to explain the association between anxiety and QoL including inflammation, ${ }^{19}$ the presence of hot flashes, ${ }^{20}$ and certain neurotransmitters. ${ }^{21,22}$ However, there are some controversies regarding the explanation of the biological and psychological plausibility of these associations. There are authors who claim that severe menopausal symptoms predispose to more anxiety and/or depression, ${ }^{20,23}$ whereas others argue the opposite, that it is the hot flashes and sleep disturbances that lead to depression and anxiety in postmenopausal women. ${ }^{24,25}$ Furthermore, research suggests that social and even geographical patterns may influence this association. ${ }^{3}$ Thus, it becomes relevant to investigate these relations in a population with particular characteristics.

Despite the fact that Latin American women have certain features that typify them as a particular group such as an earlier onset of menopause and therefore a higher exposure to hypoestrogenism, ${ }^{26}$ as well as a high prevalence of anxiety, ${ }^{27}$ we have not found research analyzing the influence of anxiety on the QoL of postmenopausal Latin American women residing in their countries of origin. Hence, the aim of the present secondary analysis was to ascertain whether there is an association between anxiety and severe QoL impairment in this postmenopausal population, controlling for demographic, clinical, anthropometric, and lifestyle variables. The results of this research may provide useful information for the comprehensive clinical management of postmenopausal women.

\section{METHODS}

\section{Study design and selection of participants}

The present document is a secondary data analysis of a cross-sectional, multicenter study from the Collaborative Group for Research of the Climacteric in Latin America (REDLINC V), which included women (pre-, peri-, and postmenopausal) residing in 11 Latin American countries and analyzed sleep problems. ${ }^{28}$ However, for this subanalysis we only included postmenopausal women: (1) 12 months or more of absent menses or (2) those post bilateral oophorectomy, as defined by the Executive Summary of Stages of Reproductive Aging Workshop. ${ }^{29}$

Participants were randomly selected from those accompanying family members seeking health care in 22 hospitals from 11 countries: México, Panamá, Paraguay, Dominican Republic, Perú, Bolivia, Chile, Ecuador, Colombia, Argentina, and Uruguay. Those aged 40 to 59 years were included and requested to fill out the surveys after being informed about the research and providing written consent. Individuals with the following conditions were excluded from the analysis: psychiatric illness under drug treatment, mental retardation, stroke sequelae, malignancy, or chronic kidney disease on hemodialysis, peritoneal dialysis or having had a kidney transplant. More details regarding the methodology used in the REDLINC V study can be consulted elsewhere. ${ }^{28}$

A total of 6,598 women were invited to participate in the REDLINC V study. 7.9\% declined participation, leaving 6,079 who gave consent and provided complete records for analysis. ${ }^{28}$ Only the data of those defined as postmenopausal were included for this secondary analysis $(n=3,503)$.

\section{Sample size and statistical power calculation}

NQuery Advisor Software version 6.0 (Statistical Solutions, Cook, Ireland) was used to calculate statistical power with a two-tailed, 95\% CI, and an estimated prevalence ratio (PR) of 1.66 based on the report of Joffe et $\mathrm{al}^{16}$ that addresses the association between anxiety and QoL in 425 mid-aged women of the Study of Women's Health Across the Nation. ${ }^{16}$ Taking into account, a $24.9 \%$ prevalence of severe QoL impairment reported by Chedraui et $\mathrm{al}^{3}$ for mid-aged Latin American women, a statistical power of $92 \%$ was estimated with 3,503 participants.

\section{Variables and measurements \\ Exposure variable: Anxiety}

The validated Spanish language version of the Goldberg Anxiety and Depression Scale was used to measure anxiety (anxiety subscale). ${ }^{30}$ This instrument consists of two subscales, one for depression and one for anxiety, each with nine items, all having dichotomous responses (yes/no). The two subscales have the same structure: four screening items and then five items that are answered only if two or more positive screening responses are encountered. Anxiety was identified as five or more positive responses including minimum two items from the screening section. The Goldberg Scale has a reported sensitivity of 0.82 , specificity of 0.91 (for either anxiety or depression) and a positive predictive value of $0.56 .^{30,31}$

\section{Response variable: quality of life}

The Menopause Rating Scale (MRS) was used to assess QoL. The tool has been translated to more than 27 languages and used worldwide. ${ }^{7,32}$ For the present research we used the Spanish language version validated in various Latin American studies. $3,8,11$

The MRS consists of 11 items that assess menopausal symptoms which are grouped into three subscales: (a) somato-vegetative-vasomotor symptoms (hot flashes), heart discomfort, sleeping problems, and muscle and joint problems; (b) psychological-depressive mood, irritability, anxiety, physical and mental exhaustion; and (c) urogenital—sexual problems, bladder problems and vaginal dryness. Each item has a Likert scale score from 0 to $4(0=$ not present, $1=$ mild, $2=$ moderate, $3=$ severe, $4=$ very severe). Scores achieved for each item are added to provide the total score of its corresponding subscale. The total MRS score is the sum of the subscale scores. A total MRS score $\geq 17$ was defined as 
severe QoL impairment. ${ }^{33}$ Heinemann et al ${ }^{7,32}$ have proposed cutoff values to define severe symptoms according to each subscale: somatic $(>8)$, psychological $(>6)$, and urogenital $(>3)$. Regarding the internal consistency of the MRS, as measured by Cronbach $\alpha$, coefficients have been found between 0.80 and 0.85 in the countries where the tool has been validated. ${ }^{34}$

\section{Measurement of control variables}

Sociodemographic variables included age (years), educational level, parity, and presence of a steady partner (yes/no). Clinical variables related to menopause included (1) the type of menopause defined as natural or surgical (by bilateral oophorectomy), (2) the postmenopausal stage was categorized as early ( $\leq 5$ years since menopause onset) or late ( $>5$ years since menopause onset) according to Stages of Reproductive Aging Workshop criteria, ${ }^{29}$ (3) the history of hysterectomy (yes/no), and (4) the current use of hormone therapy (HT) (yes/no). Other clinical variables included diabetes mellitus (yes/no), hypertension (yes/no), or arthrosis (yes/no).

Depression was measured using the depression subscale of the Goldberg Anxiety and Depression Scale (four screening items and five items to be answered only if two or more positive screening responses are encountered). Depression was defined if four or more of the responses were positive, including at least two of the screening items. ${ }^{30}$

Tobacco and alcohol consumption were included as life style variables. Smoking was categorized as never, quit a year or more ago, quit less than a year ago, and currently smokes. Alcohol habit was assessed using the Short Scale of Abnormal Drinking (Spanish acronym EBBA), which was designed to detect risky drinking through seven dichotomous (Yes/No) response items. Individuals with three or more positive responses were defined as problem drinkers. ${ }^{35}$

Body mass index (BMI) was calculated as weight in kilograms over squared height in meters $\left(\mathrm{kg} / \mathrm{m}^{2}\right)$. According to this, BMI was categorized as normal $\left(18-24.99 \mathrm{~kg} / \mathrm{m}^{2}\right)$ or increased $\left(\geq 25 \mathrm{~kg} / \mathrm{m}^{2}\right)$. Individuals with an increased BMI were further subcategorized as being overweight (25$\left.29.99 \mathrm{~kg} / \mathrm{m}^{2}\right)$ or obese $\left(\geq 30 \mathrm{~kg} / \mathrm{m}^{2}\right){ }^{36}$

\section{Ethical aspects}

The research protocol of the REDLINC V study was reviewed and approved by the Bioethics Committee of the Pro Salud de la Mujer Foundation, Santiago de Chile, Chile. The present secondary analysis was approved by the Ethics Committee of Universidad Peruana de Ciencias Aplicadas (UPC) of Lima, Perú. The primary data collection included the signing of an informed consent and the fulfillment of the guidelines recommended in the Declaration of Helsinki. ${ }^{37}$

\section{Statistical analysis}

STATA software version 11.0 (Stata Corp., College Station, TX) was used for analysis. Data are presented as mean \pm standard deviations for numeric variables (ie, age,
BMI) or absolute and relative frequencies for categorical variables. The normality of the data distribution of numerical variables was assessed with the Shapiro-Wilk test. The crude association between anxiety and severe QoL impairment and severe symptoms (according to each MRS subscale) was measured with the $\chi^{2}$ test, with previous assessment of assumptions based on expected values.

Generalized linear models with a Poisson link function and robust standard errors were used to estimate prevalence ratios and $95 \%$ CIs. A total of 12 models were developed for the four outcomes: severe QoL impairment, severe somatic symptoms, severe psychological symptoms, and severe urogenital symptoms. For each of the outcomes we performed a crude model, a statistically adjusted model (adjustment included the variables with statistically significant associations with each of the outcomes in the bivariate analysis) and an epidemiologically adjusted model (adjustment included potentially confounding variables according to the reviewed literature and directed acyclic graphs). The Newton-Raphson method was used for the measurement of maximum likelihood. For all calculations, a $P$ value of $<0.05$ was defined as statistically significant.

\section{RESULTS}

General characteristics of the postmenopausal women included in the analysis are depicted in Table 1. Mean age of the sample was $52.5 \pm 4.7$ years, $77.6 \%$ had a secondary or higher education, $8.2 \%$ had no children, and $33.4 \%$ reported having a steady partner. Also, $10.4 \%$ had diabetes mellitus, $28.0 \%$ hypertension, and $10.5 \%$ arthrosis. Nearly $60 \%$ of surveyed women were overweight or obese and $18.4 \%$ reported HT use. According to the Goldberg Scale, almost half had depression and $61.9 \%$ anxiety. $21.3 \%$ currently smoked and $2.7 \%$ were problem alcohol drinkers. $13.7 \%$ displayed severe QoL impairment (total MRS score $\geq 17$ ); and according to each MRS subscale: women presented severe symptoms in 4.5\% (somatic), $18.5 \%$ (psychological) and $25.5 \%$ (urogenital).

Frequency of severe QoL impairment (total MRS score $\geq 17$ ) and severe symptoms (for each MRS subscale) among studied women according to the presence or absence of anxiety is displayed in Fig. 1. Women with anxiety showed significantly higher rates of severe QoL impairment and more severe symptoms.

Upon bivariate analysis, severe QoL impairment was positively associated with anxiety, depression, education, parity, having a steady partner, past or current smoking, higher BMI, hypertension, and arthrosis (Table 2). Bivariate analyses of factors associated with severe symptoms (according to each MRS subscale) are presented in Table 3. Anxiety, depression, past or current smoking, higher BMI, hypertension, and arthrosis were independently and positively associated with severe symptoms of all three subscales. Severe somatic symptoms were positively associated with having a steady partner and a history of hysterectomy. Severe urogenital symptoms were positively associated with education, 


\section{NÚNEZ-PIZARRO ET AL}

TABLE 1. General characteristics of the postmenopausal women included in the analysis $(n=3,503)$

\begin{tabular}{lr}
\hline & \\
& $n(\%)$ \\
\hline Age, y & $52.5 \pm 4.7$ \\
$40-44$ & $249(7.1)$ \\
$45-49$ & $605(17.3)$ \\
$50-54$ & $1,198(34.2)$ \\
$55-59$ & $1,451(41.4)$ \\
Educational level & \\
Primary & $784(22.4)$ \\
Secondary & $1,197(34.2)$ \\
Non-university higher education & $621(17.7)$ \\
University & $901(25.7)$ \\
Has children & $3,217(91.8)$ \\
Has a stable partner & $1,171(33.4)$ \\
Surgical menopause & $434(12.4)$ \\
Postmenopausal stage, y & \\
Early ( $\leq 5)$ & $1,758(50.2)$ \\
Late $(>5)$ & $1,745(49.8)$ \\
History of hysterectomy & $956(27.3)$ \\
HT use & $645(18.4)$ \\
BMI, kg/m ${ }^{2}$ & $26.6 \pm 0.8$ \\
Normal $(18-24.99)$ & $1,429(40.8)$ \\
Overweight $(25-29.99)$ & $1,403(40.1)$ \\
Obesity ( $\geq 30)$ & $671(19.2)$ \\
Diabetes mellitus & $365(10.4)$ \\
Hypertension & $981(28.0)$ \\
Arthrosis & $368(10.5)$ \\
Smoking & \\
Never & $2,521(72.0)$ \\
Quit a year or more ago & $175(5.0)$ \\
Quit smoking <1 year ago & $378(10.8)$ \\
Currently smokes & $429(21.3)$ \\
Problem drinker & $94(2.7)$ \\
Depression ${ }^{a}$ & $1,720(49.1)$ \\
Anxiety ${ }^{a}$ & $2,167(61.9)$ \\
Quality of life (MRS) & \\
Severe impairment of quality of life (total score $\geq 17)$ & $478(13.7)$ \\
Severe somatic symptoms (score $>8)$ & $156(4.5)$ \\
Severe psychological symptoms (score $>6)$ & $648(18.5)$ \\
Severe urogenital symptoms (score $>3)$ & $893(25.5)$ \\
\hline & \\
&
\end{tabular}

Information are presented as mean \pm standard deviations or frequencies $n(\%)$. BMI, body mass index; HT, hormone therapy; MRS, Menopause Rating Scale.

${ }^{a}$ As determined with the Goldberg Anxiety and Depression Scale.

HT use, parity, having a steady partner and being in an early postmenopausal stage. Finally, severe psychological symptoms were positively associated with educational level (Table 3). Generalized linear models revealed an independent positive association between anxiety and severe QoL impairment and severe symptoms, according to epidemiological (MRS total score: PR 3.6, 95\% CI, 2.6-5.0; somatic: 5.1, 95\% CI, 2.6-10.1; psychological: 2.8, 95\% CI, 2.2-3.6, and urogenital: 1.4, 95\% CI, 1.2-1.6) and statistical criteria (MRS total score: PR 3.5, 95\% CI, 2.6-4.9; somatic: $5.0,95 \% \mathrm{CI}$, 2.5-9.9; psychological: $2.9,95 \%$ CI, 2.2-3.7, and urogenital: $1.4 ; 95 \%$ CI, 1.2-1.6) (Table 4).

\section{DISCUSSION}

These findings shows that in this postmenopausal female Latin American sample anxiety was associated with severe QoL impairment, independent of other sociodemographic, clinical, and psychological variables. It should be pointed out that this association was observed both globally (using total MRS scores to define QoL impairment) and for each of the three studied subscales of the MRS: somatic, psychological, and urogenital, although the magnitude of the association was higher with the first subscale.

Although previous studies have assessed such an association mainly among perimenopausal women, to the best of our knowledge this is the first to use the MRS to evaluate the potential influence of anxiety over QoL specifically in postmenopausal Latin American women. Therefore, it is difficult to directly compare our results with those of other studies. However, since the MRS is based on the presence and severity of a particular symptom profile, we performed an indirect analysis, focusing on the independent value of each subscale that represents a group of symptoms. As stated above, we found that the strongest association was between anxiety and severe somatic symptoms.

Our study shows that the prevalence of severe somatic symptoms in postmenopausal women with anxiety was five times higher than that observed among those without anxiety. This is consistent with results described in other studies in which a significant association between anxiety and somaticvegetative symptoms, particularly hot flashes, has been found. ${ }^{20,38}$ For example, Juang et $\mathrm{al}^{20}$ reported a strong association between anxiety and vasomotor symptoms in postmenopausal women, regardless of the presence of a sleep disorder. Mechanisms explaining this association are still not well established. However, anxiety had been correlated to increased levels of norepinephrine and serotonin, which in turn can increase the frequency of vasomotor symptoms due to their important role in thermoregulation. ${ }^{21}$ Similarly, increased proinflammatory cytokine interleukin-6 levels had been found in mid-aged women with psychological symptoms. ${ }^{19}$ This cytokine has the ability to stimulate the hypothalamic-pituitary-adrenocortical axis with the consequent release of corticotropin releasing factor, ${ }^{39}$ which could explain increased menopausal symptoms as well as cardiovascular risk. ${ }^{40}$ In fact, some studies have correlated anxiety with increased cardiovascular morbidity and mortality. ${ }^{41}$ To note, as already mentioned, is the fact that unlike our study, the association between anxiety and impaired QoL had mostly

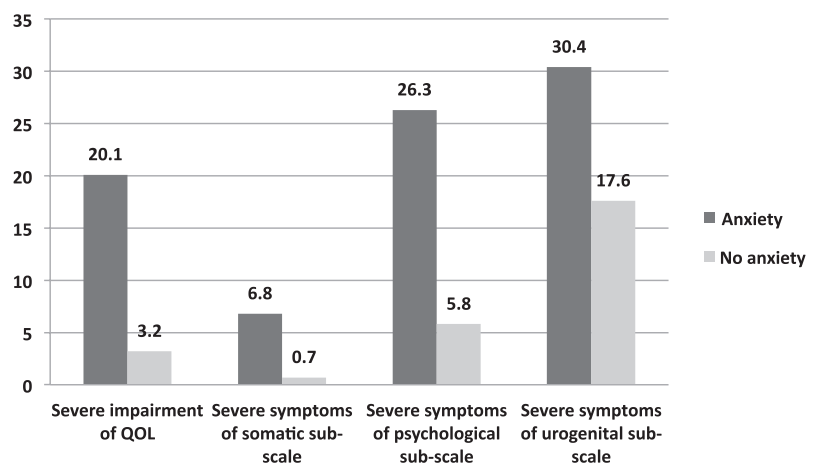

FIG. 1. Frequency of severe QoL impairment (total MRS score $>17$ ) and severe symptoms (for each MRS subscale) among studied postmenopausal women $(n=3,503)$ in accordance to the presence or not of anxiety. MRS, Menopause Rating Scale; QoL, quality of life. 
ANXIETY AND QOL IN POSTMENOPAUSAL WOMEN

TABLE 2. Factors associated with severe QoL impairment according to the MRS in women included in the analysis $(n=3,503)$

\begin{tabular}{|c|c|c|c|}
\hline & \multicolumn{3}{|c|}{ QoL } \\
\hline & With severe QoL impairment ${ }^{a} n=478$ & Without severe QoL impairment $n=3,025$ & $P^{\mathrm{b}}$ \\
\hline \multicolumn{4}{|l|}{ Anxiety } \\
\hline Without anxiety $(\mathrm{n}=1,336)$ & $43(3.2)$ & $1.93(96.8)$ & \multirow[t]{2}{*}{$<0.001$} \\
\hline With anxiety $(\mathrm{n}=2,167)$ & $435(20.1)$ & $1,732(79.9)$ & \\
\hline \multicolumn{4}{|l|}{ Depression } \\
\hline Without depression $(\mathrm{n}=1,783)$ & $91(5.1)$ & 1,692 (94.9) & \multirow[t]{2}{*}{$<0.001$} \\
\hline With depression $(\mathrm{n}=1,720)$ & $387(22.5)$ & $1,333(77.5)$ & \\
\hline \multicolumn{4}{|l|}{ HT use } \\
\hline No $(\mathrm{n}=2,858)$ & $393(13.8)$ & $2,465(86.3)$ & \multirow[t]{2}{*}{0.700} \\
\hline Yes $(n=645)$ & $85(13.2)$ & $560(86.8)$ & \\
\hline \multicolumn{4}{|l|}{ Age (years) } \\
\hline $40-44(n=249)$ & $26(10.8)$ & $214(89.2)$ & \multirow[t]{4}{*}{0.132} \\
\hline $45-49(\mathrm{n}=605)$ & $89(14.5)$ & $525(85.5)$ & \\
\hline $50-54(\mathrm{n}=1,198)$ & $181(15.1)$ & $1,017(84.9)$ & \\
\hline $55-59(\mathrm{n}=1,451)$ & $182(12.5)$ & $1,269(87.5)$ & \\
\hline \multicolumn{4}{|l|}{ Education level } \\
\hline Primary $(\mathrm{n}=784)$ & $111(14.2)$ & $672(85.8)$ & \multirow[t]{4}{*}{0.009} \\
\hline Secondary $(\mathrm{n}=1,197)$ & $167(14.0)$ & $1,030(86.0)$ & \\
\hline Non-university higher education $(\mathrm{n}=621)$ & $105(16.9)$ & $516(83.1)$ & \\
\hline University $(\mathrm{n}=901)$ & $95(10.5)$ & $806(89.5)$ & \\
\hline \multicolumn{4}{|l|}{ Parity } \\
\hline No children $(\mathrm{n}=286)$ & $25(8.2)$ & $261(91.3)$ & \multirow[t]{2}{*}{0.012} \\
\hline Parous $(\mathrm{n}=3,217)$ & $453(14.1)$ & $2,764(85.9)$ & \\
\hline \multicolumn{4}{|l|}{ Has a steady partner } \\
\hline No $(\mathrm{n}=2,332)$ & $129(11.0)$ & $1,042(89.0)$ & \multirow[t]{2}{*}{$<0.001$} \\
\hline Yes $(\mathrm{n}=1,171)$ & $349(14.9)$ & $1,983(85.0)$ & \\
\hline \multicolumn{4}{|l|}{ Type of menopause } \\
\hline Surgical $(\mathrm{n}=434)$ & $67(15.4)$ & 367 (84.6) & \multirow[t]{2}{*}{0.245} \\
\hline Natural $(\mathrm{n}=3,079)$ & $411(13.4)$ & $2,658(86.6)$ & \\
\hline \multicolumn{4}{|l|}{ Postmenopausal Stage } \\
\hline Early $(\mathrm{n}=1,758)$ & $246(14.0)$ & $1,512(86.0)$ & \multirow[t]{2}{*}{0.547} \\
\hline Late $(\mathrm{n}=1,745)$ & $232(13,3)$ & $1,513(86.7)$ & \\
\hline Hysterectomy & & & \\
\hline Yes $(\mathrm{n}=956)$ & $141(14.8)$ & 815 (85.3) & 0.244 \\
\hline No $(\mathrm{n}=2,547)$ & $337(13.2)$ & $2,210(86.8)$ & \\
\hline BMI & & & \\
\hline Normal $(\mathrm{n}=1,429)$ & $148(10.4)$ & 1,281 (89.6) & $<0.001$ \\
\hline Overweight $(\mathrm{n}=1,403)$ & $181(12.9)$ & $1,222(87.1)$ & \\
\hline Obesity $(\mathrm{n}=671)$ & $149(22.2)$ & $522(77.8)$ & \\
\hline Diabetes mellitus & & & \\
\hline Present $(\mathrm{n}=365)$ & $51(14.0)$ & $314(86.0)$ & 0.847 \\
\hline Absent $(\mathrm{n}=3,138)$ & 427 (13.6) & $2,711(86.4)$ & \\
\hline Hypertension & & & \\
\hline Present $(\mathrm{n}=981)$ & $170(17.3)$ & $811(82.7)$ & $<0.001$ \\
\hline Absent $(\mathrm{n}=2,522)$ & $308(12.2)$ & $2,214(87.8)$ & \\
\hline Arthrosis & & & \\
\hline Present $(\mathrm{n}=368)$ & $88(23.9)$ & $280(76.1)$ & $<0.001$ \\
\hline Absent $(\mathrm{n}=3,135)$ & $390(12.4)$ & 2,745 (87.6) & \\
\hline Smoking habit & & & \\
\hline Never $(\mathrm{n}=2,521)$ & $315(12.5)$ & $2,206(87.5)$ & 0.017 \\
\hline Quit $\geq 1$ year ago $(\mathrm{n}=175)$ & $28(16.0)$ & $147(84.0)$ & \\
\hline Quit $<1$ year ago $(\mathrm{n}=378)$ & $64(16.9)$ & $314(87.1)$ & \\
\hline Currently smokes $(n=429)$ & 71 (16.6) & $358(83.5)$ & \\
\hline Alcohol habit & & & \\
\hline Absent $(\mathrm{n}=3,409)$ & $460(13.5)$ & $2,949(86.5)$ & 0.115 \\
\hline Present $(n=94)$ & $18(19.2)$ & 76 (80.9) & \\
\hline
\end{tabular}

Information are presented as frequencies $n(\%)$.

BMI, body mass index; HT, hormone therapy; MRS, Menopause Rating Scale; QoL, quality of life.

${ }^{a}$ Total MRS scores $\geq 17$.

${ }^{b} P$ values obtained by the $\chi^{2}$ test.

been studied among pre- and perimenopausal women, ${ }^{16,42}$ probably because some studies reported that vasomotor symptoms were associated with fluctuating estrogenic levels. ${ }^{22,43}$ However, other authors conclude that affective disorders and vasomotor symptoms (during the menopausal transition) are associated with an imbalance of neurotransmitters $^{21,22}$ caused by estrogenic deficiency; hence, the greatest impact is expected during the postmenopausal stage. Thus, our findings, as that of others, suggest an interrelationship between anxiety and vasomotor symptoms during the 


\section{NÚNEZ-PIZARRO ET AL}

TABLE 3. Factors associated with severe symptoms according to the subscales of the MRS (somatic, psychological and urogenital)

\begin{tabular}{|c|c|c|c|c|c|c|c|c|c|}
\hline & \multicolumn{3}{|c|}{ Severe somatic symptoms } & \multicolumn{3}{|c|}{ Severe psychological symptoms } & \multicolumn{3}{|c|}{ Severe urogenital symptoms } \\
\hline & Yes $n=156$ & No $n=3,347$ & $P^{a}$ & Yes $n=648$ & No $n=2,855$ & $P^{a}$ & Yes $n=893$ & No $n=2,610$ & $P^{a}$ \\
\hline \multicolumn{10}{|l|}{ Anxiety } \\
\hline No & $9(0.7)$ & $1,327(99.3)$ & \multirow[t]{2}{*}{$<0.001$} & $78(5.8)$ & $1,258(94.2)$ & \multirow[t]{2}{*}{$<0.001$} & $235(17.6)$ & $1,101(82.4)$ & \multirow[t]{2}{*}{$<0.001$} \\
\hline Yes & $147(6.8)$ & $2,020(93.2)$ & & $570(26.3)$ & $1,597(73.7)$ & & $658(30.4)$ & 1,509 (69.6) & \\
\hline \multicolumn{10}{|l|}{ Depression } \\
\hline No & $23(1.3)$ & $1,760(98.7)$ & \multirow[t]{2}{*}{$<0.001$} & $145(8.1)$ & $1,638(91.9)$ & \multirow{2}{*}{$<0.001$} & $338(19.0)$ & $1,445(81.0)$ & \multirow{2}{*}{$<0.001$} \\
\hline Yes & $133(7.7)$ & $1,587(92.3)$ & & $503(29.2)$ & $1,217(70.8)$ & & $555(32.3)$ & $1,165(67.7)$ & \\
\hline \multicolumn{10}{|l|}{ HT use } \\
\hline No & $129(4.5)$ & $2,729(95.5)$ & \multirow[t]{2}{*}{0.716} & 522.(18.3) & $2,336(81.7)$ & \multirow[t]{2}{*}{0.453} & $693(24.3)$ & $2,165(75.7)$ & \multirow[t]{2}{*}{$<0.001$} \\
\hline Yes & $27(4.2)$ & $618(95.8)$ & & $126(19.5)$ & $519(80.5)$ & & $200(31.0)$ & $445(69.0)$ & \\
\hline \multicolumn{10}{|l|}{ Age, y } \\
\hline $40-44$ & $8(3.3)$ & $232(96.7)$ & 0.07 & $49(20.4)$ & $191(79.6)$ & 0.051 & $55(22.9)$ & $185(77.1)$ & 0.295 \\
\hline $45-49$ & $29(4.7)$ & $585(95.3)$ & & $124(20.2)$ & $490(79.8)$ & & $169(27.5)$ & $445(72.5)$ & \\
\hline $50-54$ & $67(5.6)$ & $1,131(94.4)$ & & 238 (19.9) & $960(80.1)$ & & $316(26.4)$ & $882(73.6)$ & \\
\hline $55-59$ & $52(3.6)$ & $1,399(96.4)$ & & $237(16.3)$ & $1,214(83.7)$ & & $353(24.3)$ & $1,098(75.7)$ & \\
\hline Education level & & & & & & & & & \\
\hline Primary & $44(5.6)$ & $740(94.4)$ & 0.183 & $154(19.7)$ & $630(90.3)$ & 0.014 & $192(24.6)$ & $592(75.4)$ & 0.019 \\
\hline Secondary & $50(4.2)$ & $1,147(95.8)$ & & $231(19.3)$ & $966(80.7)$ & & $294(24.6)$ & 903 (75.4) & \\
\hline $\begin{array}{l}\text { Non-university higher } \\
\text { education }\end{array}$ & $32(5.2)$ & $589(94.9)$ & & $130(20.9)$ & $491(79.1)$ & & $191(30.8)$ & $430(69.2)$ & \\
\hline University & $30(3.3)$ & $871(96.7)$ & & $133(14.8)$ & $768(85.2)$ & & $216(24.0)$ & $685(76.0)$ & \\
\hline Parity & & & & & & & & & \\
\hline No children & $12(4.2)$ & $274(95.8)$ & 0.826 & $41(14.3)$ & $245(85.7)$ & 0.058 & $58(20.3)$ & $228(79.7)$ & 0.035 \\
\hline Parous & $144(4.5)$ & $3,073(95.5)$ & & $607(8.9)$ & $2,610(81.1)$ & & $835(26.0)$ & $2,382(74.0)$ & \\
\hline Has a steady partner & & & & & & & & & \\
\hline No & $38(3.3)$ & $1,133(95.8)$ & 0.014 & $217(18.5)$ & $954(81.5)$ & 0.972 & $203(17.3)$ & $968(82.7)$ & $<0.001$ \\
\hline Yes & $118(5.1)$ & 2,214 (94.9) & & $431(18.5)$ & $1,901(81.5)$ & & $690(29.6)$ & $1,642(70.4)$ & \\
\hline Type of menopause & & & & & & & & & \\
\hline Surgical & $23(5.3)$ & $411(94.7)$ & 0.361 & 95 (21.9) & $339(78.1)$ & 0.052 & $116(26.7)$ & $318(73.3)$ & 0.528 \\
\hline Natural & $133(4.3)$ & $2,936(95.7)$ & & $553(18.0)$ & $2,516(82.0)$ & & $777(25.3)$ & $2,292(74.7)$ & \\
\hline Postmenopausal stage & & & & & & & & & \\
\hline Early & $81(4.6)$ & $1,677(95.4)$ & 0.657 & $331(18.8)$ & $1,427(81.2)$ & 0.614 & 475 (27) & $1,283(73)$ & 0.037 \\
\hline Late & $75(4.3)$ & $1,670(95.7)$ & & 317 (18.2) & $1,428(81.8)$ & & $418(24)$ & $1,327(76)$ & \\
\hline Hysterectomy & & & & & & & & & \\
\hline Yes & $66(6.9)$ & $890(93.1)$ & $<0.001$ & $195(20.4)$ & 761 (79.6) & 0.076 & $256(26.8)$ & $700(73.2)$ & 0.285 \\
\hline No & $90(3.5)$ & $2,457(96.5)$ & & $453(17.8)$ & $2,094(82.2)$ & & $637(25.0)$ & $1,910(75.0)$ & \\
\hline BMI & & & & & & & & & \\
\hline Normal & $43(3.0)$ & $1,386(97.0)$ & $<0.001$ & $225(15.8)$ & $1,024(84.3)$ & $<0.001$ & $336(23.5)$ & $1,093(76.5)$ & 0.004 \\
\hline Overweight & $64(4.6)$ & $1,339(95.4)$ & & $255(18.2)$ & $1,148(81.8)$ & & $354(25.2)$ & $1,049(74.8)$ & \\
\hline Obesity & $49(7.3)$ & $622(92.7)$ & & $168(25.0)$ & $503(75.0)$ & & $203(30.3)$ & $468(69.7)$ & \\
\hline Diabetes mellitus & & & & & & & & & \\
\hline Absent & $137(4.4)$ & 3,001 (95.6) & 0.462 & $571(18.2)$ & $2,567(81.8)$ & 0.177 & $789(25.1)$ & $2,349(74.7)$ & 0.165 \\
\hline Present & $19(5.2)$ & $346(94.8)$ & & $77(21.1)$ & $288(78.9)$ & & $104(28.5)$ & $261(71.5)$ & \\
\hline Hypertension & & & & & & & & & \\
\hline Absent & $99(3.9)$ & $2,423(96.1)$ & 0.015 & $443(17.8)$ & $2,079(82.4)$ & 0.023 & $619(24.6)$ & $1,903(75.5)$ & 0.039 \\
\hline Present & $57(5.8)$ & 924 (94.2) & & $205(20.9)$ & 776 (79.1) & & $274(27.9)$ & $707(72.1)$ & \\
\hline Arthrosis & & & & & & & & & \\
\hline Absent & $119(3.8)$ & $3,016(96.2)$ & $<0.001$ & $554(17.8)$ & $2,581(82.3)$ & $<0.001$ & $767(24.5)$ & 2,368 (75.5) & $<0.001$ \\
\hline Present & $37(10)$ & $331(90)$ & & $94(25.5)$ & $274(74.5)$ & & $126(34.2)$ & $242(65.8)$ & \\
\hline Smoking habit & & & & & & & & & \\
\hline Never has smoked & $98(3.9)$ & $2,423(96.1)$ & 0.015 & $424(16.8)$ & $2,097(83.2)$ & 0.001 & $629(25)$ & $1,892(75)$ & 0.013 \\
\hline Quit $\geq 1$ year & $15(8.6)$ & 160 (91.4) & & $37(21.1)$ & 138 (78.9) & & $41(23.4)$ & $134(76.6)$ & \\
\hline Quit $<1$ year & $21(5.6)$ & $357(94.4)$ & & $84(22.2)$ & $294(77.8)$ & & $122(32.3)$ & $256(67.7)$ & \\
\hline Currently smokes & $22(5.1)$ & $407(94.9)$ & & $103(24.0)$ & $326(76.0)$ & & $101(23.6)$ & $328(76.5)$ & \\
\hline Alcohol habit & & & & & & & & & \\
\hline Absent & $148(4.3)$ & 3,261 (95.7) & 0.053 & $625(18.3)$ & $2,784(81.7)$ & 0.131 & $866(25.4)$ & $2,543(74.6)$ & 0.466 \\
\hline Present & $8(8.5)$ & $86(91.5)$ & & $23(24.5)$ & $71(75.5)$ & & $27(28.7)$ & $67(71.3)$ & \\
\hline
\end{tabular}

Information are presented as frequencies $n(\%)$.

BMI, body mass index; HT, hormone therapy; MRS, Menopause Rating Scale

${ }^{a} P$ values obtained by the $\chi^{2}$ test.

postmenopausal stage. This leads us to speculate that they have similar pathophysiological mechanisms.

Similarly, a significant association between anxiety and the presence of severe urogenital symptoms was found in our study. Interestingly, although the frequency of severe urogenital symptoms was higher in women with anxiety, as compared to somatic and psychological ones (30.4\% vs $6.8 \%$ and $26.3 \%$, respectively, Fig. 1); regression models found that the association between urogenital symptoms and anxiety was the weakest (Table 4). There is no defined mechanism to 
ANXIETY AND QOL IN POSTMENOPAUSAL WOMEN

TABLE 4. Association between anxiety and severe QoL impairment and symptoms severity (MRS) in the studied population ( $n=3,503)$

\begin{tabular}{|c|c|c|c|c|c|c|c|c|}
\hline & \multicolumn{2}{|c|}{ Crude } & \multicolumn{2}{|c|}{$\begin{array}{c}\text { Adjusted } \\
\text { reduced (epide- } \\
\text { miological } \\
\text { models) }\end{array}$} & \multirow[b]{2}{*}{$P$} & \multicolumn{2}{|c|}{$\begin{array}{l}\text { Adjusted } \\
\text { reduced (statisti- } \\
\text { cal models) }\end{array}$} & \multirow[b]{2}{*}{$P$} \\
\hline & PR & $95 \% \mathrm{CI}$ & PR & $95 \% \mathrm{CI}$ & & PR & $95 \% \mathrm{CI}$ & \\
\hline \multicolumn{9}{|c|}{ Anxiety and severe QoL impairment (total MRS score $\geq 17$ ) } \\
\hline Without anxiety & Base & & Base & & & Base & & \\
\hline With anxiety & 6.2 & 4.6-8.5 & $3.6^{a}$ & $2.6-5$ & $<0.001$ & $3.5^{b}$ & $2.6-4.9$ & $<0.001$ \\
\hline \multicolumn{9}{|c|}{ Anxiety and presence of severe somatic symptoms (score $>8$ ) } \\
\hline Without anxiety & Base & & Base & & & Base & & \\
\hline With anxiety & 10.1 & $5.2-19.7$ & $5.1^{c}$ & $2.6-10.1$ & $<0.001$ & $\mathbf{5}^{d}$ & 2.5-9.9 & $<0.001$ \\
\hline \multicolumn{9}{|c|}{ Anxiety and presence of severe psychological symptoms (score $>6$ ) } \\
\hline Without anxiety & Base & & Base & & & Base & & \\
\hline With anxiety & 4.5 & $3.6-5.7$ & $\mathbf{2 . 8 ^ { e }}$ & $2.2-3.6$ & $<0.001$ & $2.9^{f}$ & $2.2-3.7$ & $<0.001$ \\
\hline \multicolumn{9}{|c|}{ Anxiety and presence of severe urogenital symptoms (score $>3$ ) } \\
\hline Without anxiety & Base & & Base & & & Base & & \\
\hline With anxiety & 1.7 & $1.5-2$ & $1.4^{g}$ & $1.2-1.6$ & $<0.001$ & $1.4^{h}$ & $1.2-1.6$ & $<0.001$ \\
\hline
\end{tabular}

The bold values represent the prevalence ratio (PR) adjusted to the epidemiological and statistical model.

BMI, body mass index; HT, hormone therapy; MRS, Menopause Rating Scale; PR, prevalence ratio; QoL, quality of life.

${ }^{a}$ Epidemiological model adjusted as per age, educational level, presence of diabetes, hypertension, arthrosis, menopausal stage, BMI, smoking habit, and depression.

${ }^{b}$ Statistical model adjusted per variables that had a significant association with severe QoL impairment during bivariate analysis (QoL impairment:

educational level, having a partner, parity, BMI, hypertension, arthrosis, smoking habit, and depression).

${ }^{c}$ Epidemiological model adjusted as per age, educational level, presence of diabetes, hypertension, arthrosis, menopausal stage, BMI, smoking habit, and depression.

${ }^{d}$ Statistical model adjusted by the variables that had a significant association with severe somatic symptoms (MRS) in bivariate analysis (partner, hysterectomy, BMI, hypertension, arthrosis, smoking habits, and depression).

${ }^{e}$ Epidemiological model adjusted as per age, educational level, presence of diabetes, hypertension, arthrosis, menopausal stage, BMI, smoking habit, and depression.

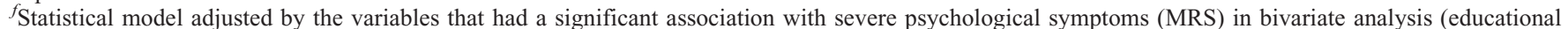
level, BMI, hypertension, arthrosis, smoking habits, and depression).

${ }^{g}$ Epidemiological model adjusted as per age, educational level, presence of diabetes, hypertension, arthrosis, menopause stage, BMI, smoking habit, and depression.

${ }^{h}$ Statistical model adjusted by the variables that had a significant association with severe urogenital symptoms (MRS) during bivariate analysis (HT use, educational level, parity, has a partner, menopausal stage, BMI, hypertension, arthrosis, smoking habit, and depression).

explain this association; however, Alexander et $\mathrm{al}^{40}$ had reported that stress, through corticotropin-releasing hormone and peptides derived from proopiomelanocortin, inhibits the release of gonadotropin-releasing hormone, thus decreasing estrogen levels and its action at the tissue level. This may partially explain our findings. On the other hand, one should recall that vaginal dryness has an inverse relationship to serum estradiol levels. ${ }^{2}$ Nevertheless, this is a relatively understudied topic that requires further research.

Regarding the limitations of our study, first, its crosssectional design does not allow establishing causality. Second, our study focused on native Spanish-speaking women; hence, results cannot be extrapolated to other populations. Nevertheless, it provides a baseline for future studies. There are reports suggesting that ethnicity influences QoL within the mid-aged female Latin American population. ${ }^{10,11}$ However, ethnicity was not considered in our study, and therefore may also be considered a potential limitation. Also important is the fact that the Goldberg Scale, used to measure anxiety, is a screening one; hence, our results should be interpreted with caution as the scale could over- or underestimate its actual frequency in our population. Finally, one must mention a possible existing colinearity between MRS and Goldberg Scale scores, especially the psychological MRS subscale that includes two items that assess the presence of depression and anxiety. Nevertheless, first, analysis was carried out with total MRS scores and also independently with subscale scores, after which the strongest association was observed between anxiety and severe somatic symptoms; and second, statistical analysis evaluating possible collinearity of the generalized linear models yielded negative results. ${ }^{44}$

Despite the aforementioned limitations, to the best of our knowledge, the present study is the first to evaluate the association between anxiety and QoL in a large sample of postmenopausal women using a specific tool to assess menopausal symptoms, the MRS. Due to obvious implications, studying factors affecting QoL is highly relevant; moreover, if we bear in mind that in this population menopause onset had been reported to occur earlier than in other populations. ${ }^{3,26}$ In addition, the high number of studied women gives our study a further added value.

\section{CONCLUSIONS}

Anxiety was independently associated with severe QoL impairment in this postmenopausal Latin American sample. A strong association was found between anxiety and severe somatic symptoms, which include hot flashes, sleep disorders and muscle and joint complaints. Thus, screening for anxiety in this population becomes relevant in clinical practice. However, there is a need to conduct longitudinal studies to 


\section{NÚNEZ-PIZARRO ET AL}

determine the causality of this association and the benefit of early detection of anxiety in this group of women.

Acknowledgments: Original version of this article was translated by Kim Hoffman, PhD, a native English speaker and Senior Research Associate at Oregon Health and Science University.

\section{REFERENCES}

1. Goodman NF, Cobin RH, Ginzburg SB, Katz IA, Woode DE. American Association of Clinical Endocrinologists Medical Guidelines for Clinical Practice for the diagnosis and treatment of menopause: executive summary of recommendations. Endocr Pract Off J Am Coll Endocrinol Am Assoc Clin Endocrinol 2011;17:949-954.

2. Dennerstein L, Lehert P, Guthrie JR, Burger HG. Modeling women's health during the menopausal transition: a longitudinal analysis. Menopause 2007; 14:53-62.

3. Chedraui P, Blumel JE, Baron G, et al. Impaired quality of life among middle aged women: a multicentre Latin American study. Maturitas 2008;61:323-329.

4. López AF, Soares De Lorenzi DR, d'Andretta Tanaka AC. Calidad de vida de mujeres en fase de transición menopaúsica evaluado por la Menopause Rating Scale (MRS) [in Spanish]. Rev Chil Obstet Ginecol 2010;75:375-382

5. Chen Y, Lin S-Q, Wei Y, Gao H-L, Wang S-H, Wu Z-L. Impact of menopause on quality of life in community-based women in China Menopause 2008; 15:144-149.

6. Blumel JE, Castelo-Branco C, Binfa L, et al. Quality of life after the menopause: a population study. Maturitas 2000;34:17-23

7. Heinemann LA, DoMinh T, Strelow F, Gerbsch S, Schnitker J, Schneider HP. The Menopause Rating Scale (MRS) as outcome measure for hormone treatment? A validation study. Health Qual Life Outcomes 2004;2:67.

8. Chedraui P, Aguirre W, Hidalgo L, Fayad L. Assessing menopausal symptoms among healthy middle aged women with the Menopause Rating Scale. Maturitas 2007;57:271-278.

9. Avis NE, Stellato R, Crawford S, et al. Is there a menopausal syndrome? Menopausal status and symptoms across racial/ethnic groups. Soc Sci Med 1982 2001;52:345-356.

10. Ojeda E, Blumel JE, Vallejo MS, Lavin P. Climacteric symptoms in Quechua and Mestizo women from the Andean region of Cusco, Peru: effects of altitude and ethnicity. Maturitas 2014;77:356-360.

11. Monterrosa A, Blumel JE, Chedraui P. Increased menopausal symptoms among Afro-Colombian women as assessed with the Menopause Rating Scale. Maturitas 2008;59:182-190.

12. Gartoulla P, Worsley R, Bell RJ, Davis SR. Moderate to severe vasomotor and sexual symptoms remain problematic for women aged 60 to 65 years. Menopause 2015;22:694-701

13. Hunter MS, Gentry-Maharaj A, Ryan A, et al. Prevalence, frequency and problem rating of hot flushes persist in older postmenopausal women: impact of age, body mass index, hysterectomy, hormone therapy use, lifestyle and mood in a cross-sectional cohort study of 10,418 British women aged 54-65. BJOG Int J Obstet Gynaecol 2012;119:40-50.

14. Blumel JE, Fica J, Chedraui P, et al. Sedentary lifestyle in middle-aged women is associated with severe menopausal symptoms and obesity. Menopause 2016;23:488-493.

15. Bromberger JT, Kravitz HM, Chang Y, et al. Does risk for anxiety increase during the menopausal transition? Study of Women's Health Across the Nation (SWAN). Menopause 2013;20:488-495.

16. Joffe H, Chang Y, Dhaliwal S, et al. Lifetime history of depression and anxiety disorders as a predictor of quality of life in midlife women in the absence of current illness episodes. Arch Gen Psychiatry 2012;69:484-492

17. Reis FMCV, Pestana-Oliveira N, Leite CM, et al. Hormonal changes and increased anxiety-like behavior in a perimenopause-animal model induced by 4-vinylcyclohexene diepoxide (VCD) in female rats. Psychoneuroendocrinology 2014;49:130-140.

18. Freeman EW, Sammel MD, Lin H, Gracia CR, Kapoor S. Symptoms in the menopausal transition: hormone and behavioral correlates. Obstet Gynecol 2008;111:127-136.

19. Yasui T, Maegawa M, Tomita J, et al. Association of serum cytokine concentrations with psychological symptoms in midlife women. J Reprod Immunol 2007;75:56-62.
20. Juang K-D, Wang S-J, Lu S-R, Lee S-J, Fuh J-L. Hot flashes are associated with psychological symptoms of anxiety and depression in peri- and post- but not premenopausal women. Maturitas 2005;52: 119-126.

21. Berendsen HH. The role of serotonin in hot flushes. Maturitas 2000;36:155-164.

22. Rossmanith WG, Ruebberdt W. What causes hot flushes? The neuroendocrine origin of vasomotor symptoms in the menopause. Gynecol Endocrinol Off J Int Soc Gynecol Endocrinol 2009;25:303-314.

23. Thurston RC, Blumenthal JA, Babyak MA, Sherwood A. Emotional antecedents of hot flashes during daily life. Psychosom Med 2005;67: 137-146.

24. Lipovac M, Chedraui P, Gruenhut C, Gocan A, Stammler M, Imhof M. Improvement of postmenopausal depressive and anxiety symptoms after treatment with isoflavones derived from red clover extracts. Maturitas 2010;65:258-261.

25. Llaneza P, Garcia-Portilla MP, Llaneza-Suarez D, Armott B, Perez-Lopez FR. Depressive disorders and the menopause transition. Maturitas 2012;71:120-130.

26. Castelo-Branco C, Blumel JE, Chedraui P, et al. Age at menopause in Latin America. Menopause 2006;13:706-712.

27. Gaviria SL, Rondon MB. Some considerations on women's mental health in Latin America and the Caribbean. Int Rev Psychiatry Abingdon Engl 2010;22:363-369.

28. Blumel JE, Cano A, Mezones-Holguin E, et al. A multinational study of sleep disorders during female mid-life. Maturitas 2012;72:359-366.

29. Harlow SD, Gass M, Hall JE, et al. Executive summary of the stages of reproductive aging Workshop +10 : addressing the unfinished agenda of staging reproductive aging. J Clin Endocrinol Metab 2012;97:1159-1168.

30. Montón C, Pérez-Echevarría M, Campos R, García J, Lobo A. Escalas de ansiedad y depresión de Goldberg: una guía de entrevista eficaz para la detección del malestar psíquico. Aten Primaria 1993;12:345-349.

31. Goldberg D, Bridges K, Duncan-Jones P, Grayson D. Detecting anxiety and depression in general medical settings. BMJ 1988;297:897-899.

32. Heinemann LA, Potthoff P, Schneider HP. International versions of the Menopause Rating Scale (MRS). Health Qual Life Outcomes 2003;1:28.

33. Ref_Values_CountrGr.pdf. http://www.menopause-rating-scale.info/ documents/Ref_Values_CountrGr.pdf. Accessed April 26, 2016.

34. Heinemann K, Ruebig A, Potthoff P, et al. The Menopause Rating Scale (MRS) scale: a methodological review. Health Qual Life Outcomes 2004;2:45

35. Orpinas P, Valdés M, Pemjeam A, Florenzano R, Nogueira R, Hernández J. Validación de una escala breve para la detección de beber anormal (EBBA). In: Florenzano R, Horwitz N, Penna M, eds. et al. Temas Salud Ment Aten Primaria Salud. Santiago, Chile: CPU; 1991:185-193.

36. Deurenberg P, Weststrate JA, Seidell J. Body mass index as a measure of body fatness: age- and sex- specific prediction formulas. $\mathrm{Br} \mathrm{J} \mathrm{Nutr}$ 1991:65:105-114

37. World Medical Association. World Medical Association Declaration of Helsinki: ethical principles for medical research involving human subjects. JAMA 2013;310:2191-2194.

38. Terauchi M, Hiramitsu S, Akiyoshi M, et al. Associations between anxiety, depression and insomnia in peri- and post-menopausal women. Maturitas 2012;72:61-65.

39. Besedovsky HO, del Rey A. Immune-neuro-endocrine interactions: facts and hypotheses. Endocr Rev 1996;17:64-102.

40. Alexander J, Dennerstein L, Woods NF, et al. Role of stressful life events and menopausal stage in wellbeing and health. Expert Rev Neurother 2007; 7:93-113.

41. Smoller JW, Pollack MH, Wassertheil-Smoller S, et al. Panic attacks and risk of incident cardiovascular events among postmenopausal women in the Women's Health Initiative Observational Study. Arch Gen Psychiatry 2007;64:1153-1160.

42. Bromberger JT, Assmann SF, Avis NE, Schocken M, Kravitz HM, Cordal A. Persistent mood symptoms in a multiethnic community cohort of preand perimenopausal women. Am J Epidemiol 2003;158:347-356.

43. Rodstrom K, Bengtsson C, Lissner L, Milsom I, Sundh V, Bjorkelund C. A longitudinal study of the treatment of hot flushes: the population study of women in Gothenburg during a quarter of a century. Menopause 2002;9:156-161.

44. Vatcheva KP, Lee M, McCormick JB, Rahbar MH. Multicollinearity in regression analyses conducted in epidemiologic studies. Epidemiol Open Access 2016;6:227. 